\title{
Analysis of Steel Bars in Corrosion Process after 70 Years of Natural Aging
}

\author{
Francieli Schmoeller ${ }^{1}$, Maryangela G. Lima ${ }^{2}$ and Silvelene A. Silva ${ }^{3}$ \\ ${ }^{1}$ Instituto Tecnológico de Aeronáutica (ITA), Dept. of Civil Engineering, Marechal Eduardo Gomes \\ Sq., 50, 12228-900, São José dos Campos-SP, Brazil, francieli.schmoeller@gmail.com \\ ${ }^{2}$ Instituto Tecnológico de Aeronáutica (ITA), Dept. of Civil Engineering, Marechal Eduardo Gomes \\ Sq., 50, 12228-900, São José dos Campos-SP, Brazil, magdlima@gmail.com \\ ${ }^{3}$ Instituto de Estudos Avançados (IEAv), St. Coronel Aviador José Alberto Albano do Amarante, 01, \\ 12228-001, São José dos Campos-SP, Brazil, lenisoni@uol.com.br
}

\begin{abstract}
Reinforced concrete structures are commonly used in civil engineering. However, the number of deteriorations in these structures is increasing, especially problems related to steel corrosion. Also, according studies, corrosion is responsible for about $3.5 \%$ of annual GDP with recovery costs in world. Thus, this study analyzed the corrosion of steel bars at 70-year-old, which are in corrosion process by natural aging. Tests were performed to analyze the bars microstructure, using SEM and EDS, as well as analysis of the current mechanical characteristics, with tensile test. Through $S E M$, it was possible to measure the layer of the corrosion products formed at the samples edge, and to observe the fragility of this region, with the presence of several microcracks. EDS test contributed to verify the oxygen difference from the nucleus until to the specimen edge. It was possible to notice that in the edge, presence of oxygen is much greater. In the mechanical tests, by the tensile test, the samples do not reach the minimum elongation and the limit of resistance prescribed in the standard. Thus, it is believed after 70 years of natural aging, the samples are in advanced process of corrosion, with edges worn out, and no comply with the minimum mechanical requirements.
\end{abstract}

Keywords: Corrosion, Steel Bars, Microstructure, Deterioration, Natural Aging.

\section{Introduction}

Reinforced concrete is one of the structural elements most used in construction worldwide. Consequently, the incidence of pathological manifestations that deteriorate this type of structure is increasing, mainly problems related with corrosion. In addition, corrosion causes a lot of damage to the global economic sector, generating a high cost of recovery. It is estimated that around $3.5 \%$ of world GDP is spent annually on corrosion (SCHMITT et al., 2009; KOCH et al., 2016).

Corrosion is considered a destructive interaction of a material with its environment, usually occurring in aqueous environment, known as electrochemical corrosion. In this degradation, oxidation and reduction reactions occur, forming an electric current and an ionic current. Insomuch, it is possible to form iron oxides and hydroxides, which deposit on rebar surface and are called corrosion products.

One of variables that favor corrosion is the $\mathrm{pH}$ of the environment, which is responsible for enhancing this degradation. As stated by Mehta and Monteiro (2006), from the moment the concrete $\mathrm{pH}$ becomes lower than 11.5, the passivation film on rebar is broken, which 
allows the beginning of corrosion. After the steel depassivation, the corrosion propagation phase begins, with the development of the corrosive process, in which each material reacts and has a particular deterioration velocity (SOUZA and RIPPER, 1998).

Thus, there is a relation as $\mathrm{pH}$ function, which is represented in E-pH diagram, known as the Pourbaix diagram (1974). In this diagram, the $\mathrm{pH}$ conditions are established in relation to the potential that take the material to three distinct situations: the immunity region, which independent of $\mathrm{pH}$, the steel has a very low corrosion potential, being protected; the passivation area, which the armor has the protective layer; and corrosion, located in circumstances of more acidic $\mathrm{pH}$, which the reinforcement depassivation occurs and, consequently, its deterioration.

Also, there are two main aggressive agents helping in reinforcement depassivation: the carbonation of concrete and the presence of chloride ions. Carbonation involves the penetration of carbon dioxide $\left(\mathrm{CO}_{2}\right)$ into the concrete by diffusion, resulting in a gradual decrease of $\mathrm{pH}$. It is ranging from 12.5-13.5 to a pH close 9, thus losing its high alkalinity (LIMA, 1996).

Other aggressive agent is chloride $\left(\mathrm{Cl}^{-}\right)$ions, penetrating or embedded in the concrete, which reach the steel, resulting in the reinforcement depassivation even with the high $\mathrm{pH}$ (LIMA, 1996). Thereby, the presence of chlorides ions especially in marine exposure and the loss of alkalinity due to the carbonation of the concrete can destroy the passive film that protects the steel and induce its corrosion (BOSSIO et al., 2015).

Tutti (1982) proposed what currently is considered the classical model of reinforcement concrete structure life cycle, which period of life cycle is considered as the sum of the
corrosion initiation and propagation periods, until the moment the structure needs correction.
Moreover, any loss of rebar protection affects signifieantly the durability and service life of
reinforced concrete structures and may compromise and even induce to co/lapse.
Necessity to bette understand this degradation process, in order to improve the duality and performance of structures, resulted in the microstructural study of steel bars at 70-year-

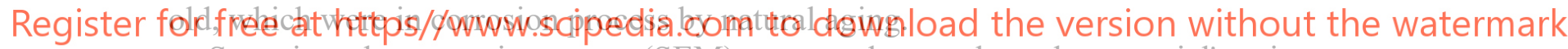
Scanning electron microscopy (SEM) was used to analyze the material's microstructure. Energy Dispersive X-Ray Spectroscopy (EDS) was utilized to examine the difference in chemical composition between the grains and the layer of corrosion products formed on the surface. In addition, the mechanical tensile test was performed to obtain the current mechanical state of the specimens.

\section{Materials and Methods}

This chapter will present the materials that composed the sample of the study, as well as the methodology used to achieve the intended tests.

\subsection{Materials}

Three bars composed the specimens, belonging to foundation block of ITA's building. The bars were smooth, originally had a nominal diameter of $15.88 \mathrm{~mm}(5 / 8$ ”), and were named $\mathrm{B} 1, \mathrm{~B} 2$ and $\mathrm{B} 6$. 


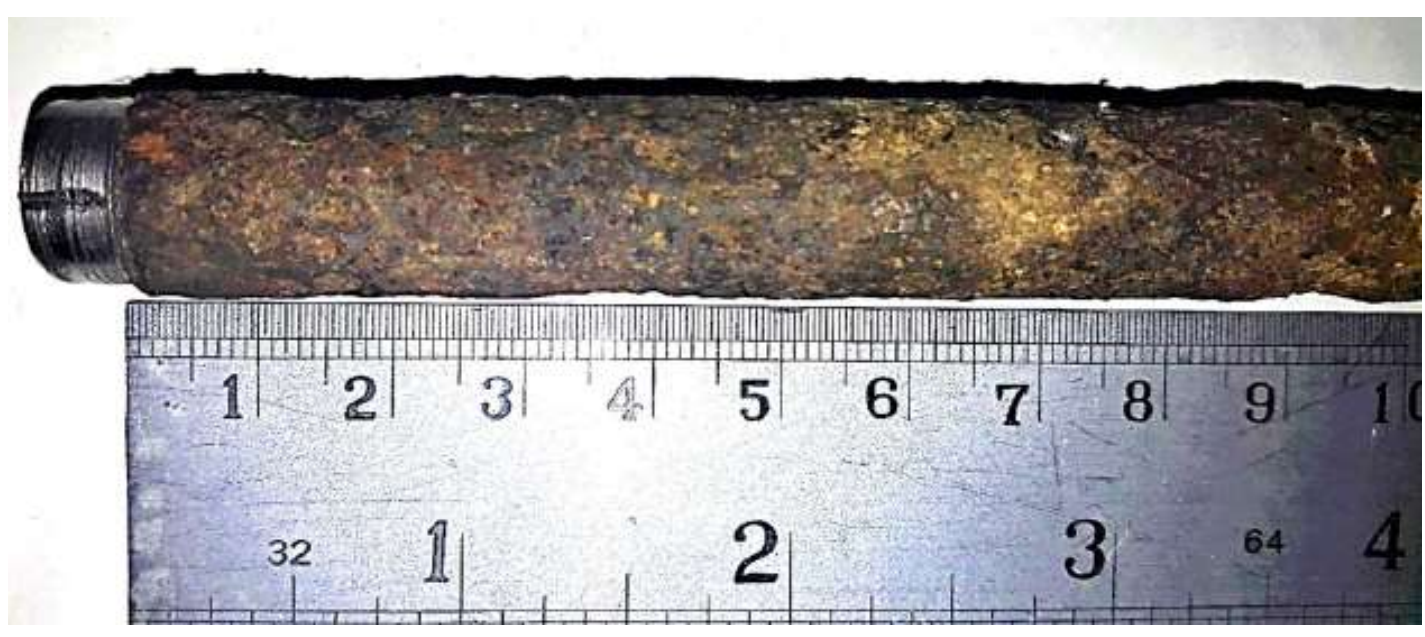

Figure 1. Specimen B2 before preparation and cutting.

These bars remained underground and unloaded for approximately a period 60 years, from their construction to 2008, when the samples were collected and stocked in the Materials Laboratory of the Civil Engineering Department. Currently, these bars have about 70 years of natural aging.

\subsection{Methods}

Methodology used in th which were in corrosion proces

proposed analyses.

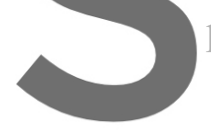

Register for free at https//www.scipedia.com toldøwhload the version without the watermark

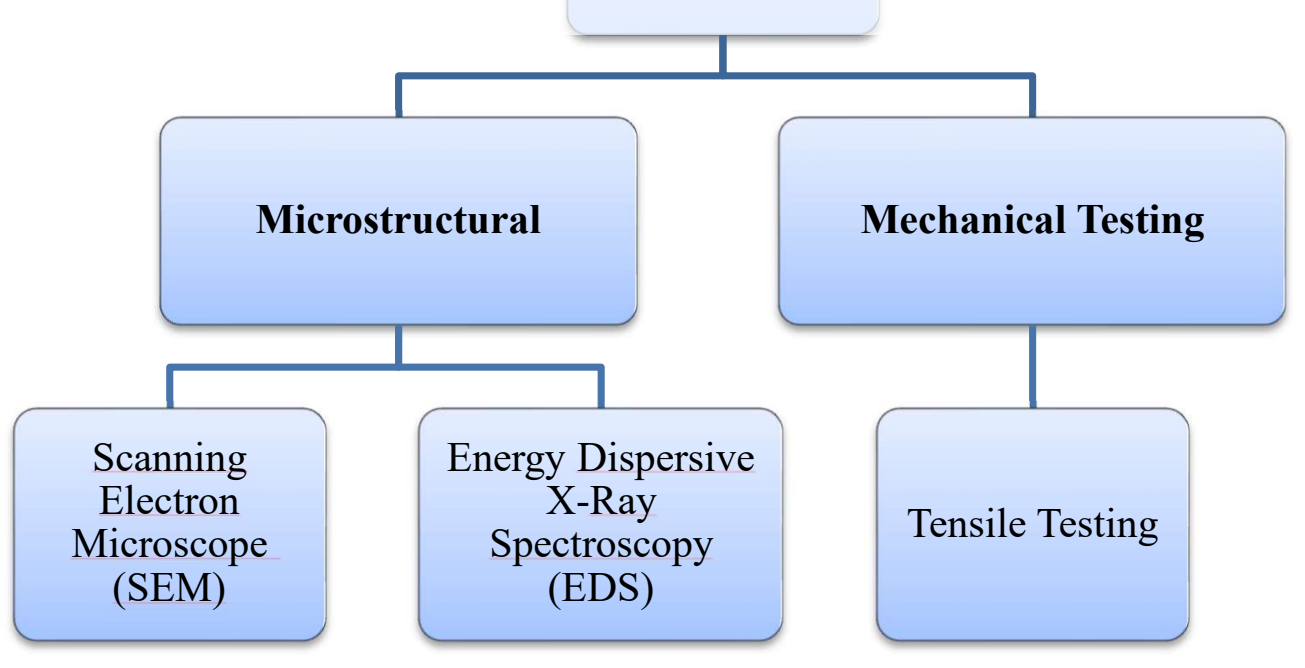

Figure 2. Flowchart with studies performed. 


\subsubsection{Microstructural Analysis}

Scanning electron microscopy (SEM) was used to analyze the general structure of the samples, allowing the visualization of grains and grain boundaries. Thus, the bars were cut to $10 \mathrm{~mm}(0.39$ in.) in length and metallographic preparation was performed to preserve the corroded edges.

Analysis by energy dispersive X-ray spectroscopy (EDS) using the Linescan technique allowed the comparison of samples chemical composition between the grains not corroded in relation to the layer of corrosion products. For this test, were used the same samples of the SEM.

\subsubsection{Mechanical Testing}

Tensile test was carried out on samples of $210 \mathrm{~mm}$ in length, seeking to analyze the behavior of the material during the test until its runture. Therefore, it is possible to analyze the current resistance of the bars and compare with the minimum resistance required by the standard.

\section{Results and Discussion}

This chapter will present and analyze the results obtained from the methodology described in the previous chapter.

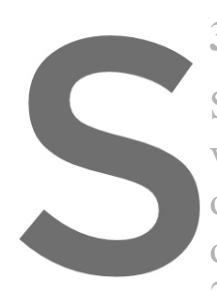
3.1 Microstructural Analysis
Scanning electron microscopy resulted in
verification of the structure formed by the g
observe the homogeneity in the grain structure
observed, some grains are lighter than others, 2006). The following image shows the result obtained by microscopy.

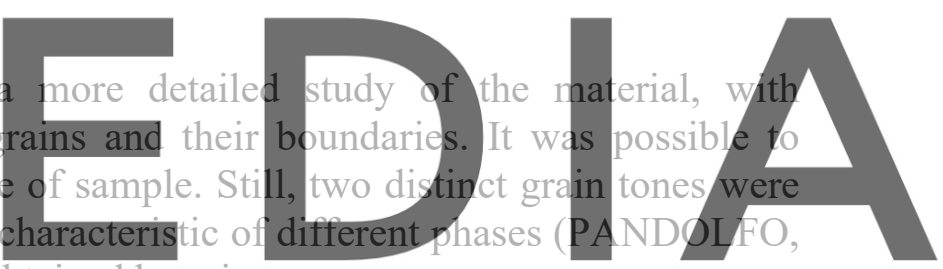

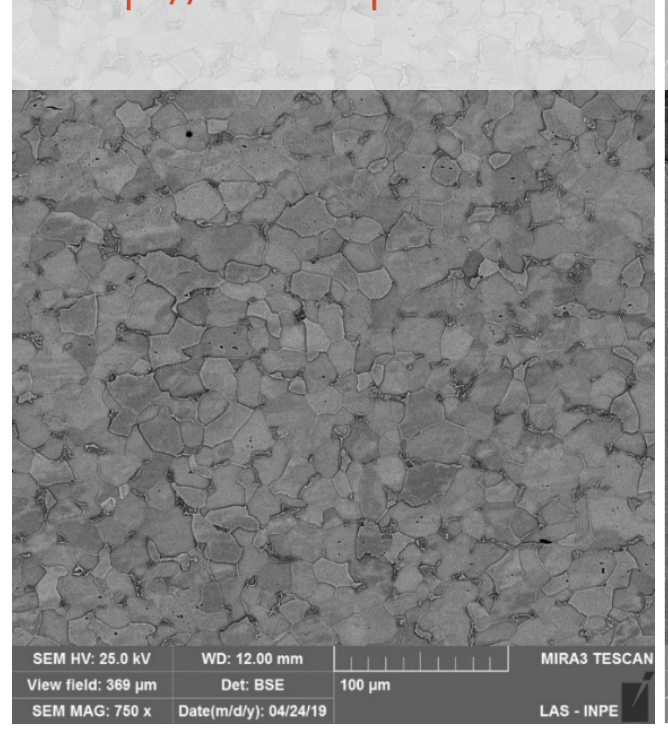

(a)

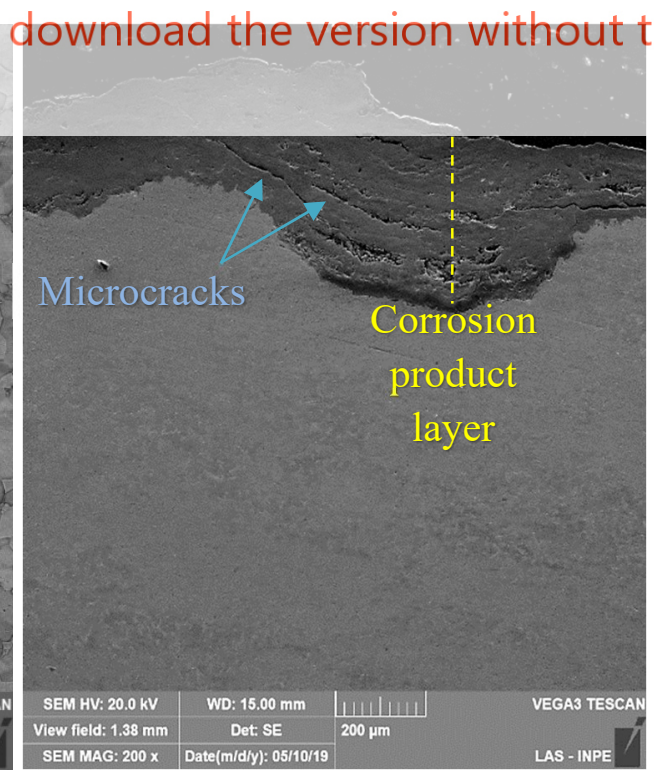

(b)

Figure 3. SEM image (a) at center of the sample (b) of corrosion product layer. 
Figure (a) was obtained through the backscattered detector, which allows verifying broadly the material configuration. SEM also showed the presence of the corrosion product layer formed on surface of the samples, as shown in (b). Corrosion product layer found in the bars showed irregular wear at the edges, as well as different corrosion depths. Thickness of corrosion layer ranged from $62.38 \mu \mathrm{m}$ to $381.20 \mu \mathrm{m}$. Also, several microcracks and various micropores were visualized in this corrosion layer, showing fragility of this material.

Through X-ray dispersive energy spectroscopy analysis, using the Linescan technique, verified the variation in concentration of main chemical elements. For this, was defined in sample a line from the center to the corrosion layer, as shown in Figure .
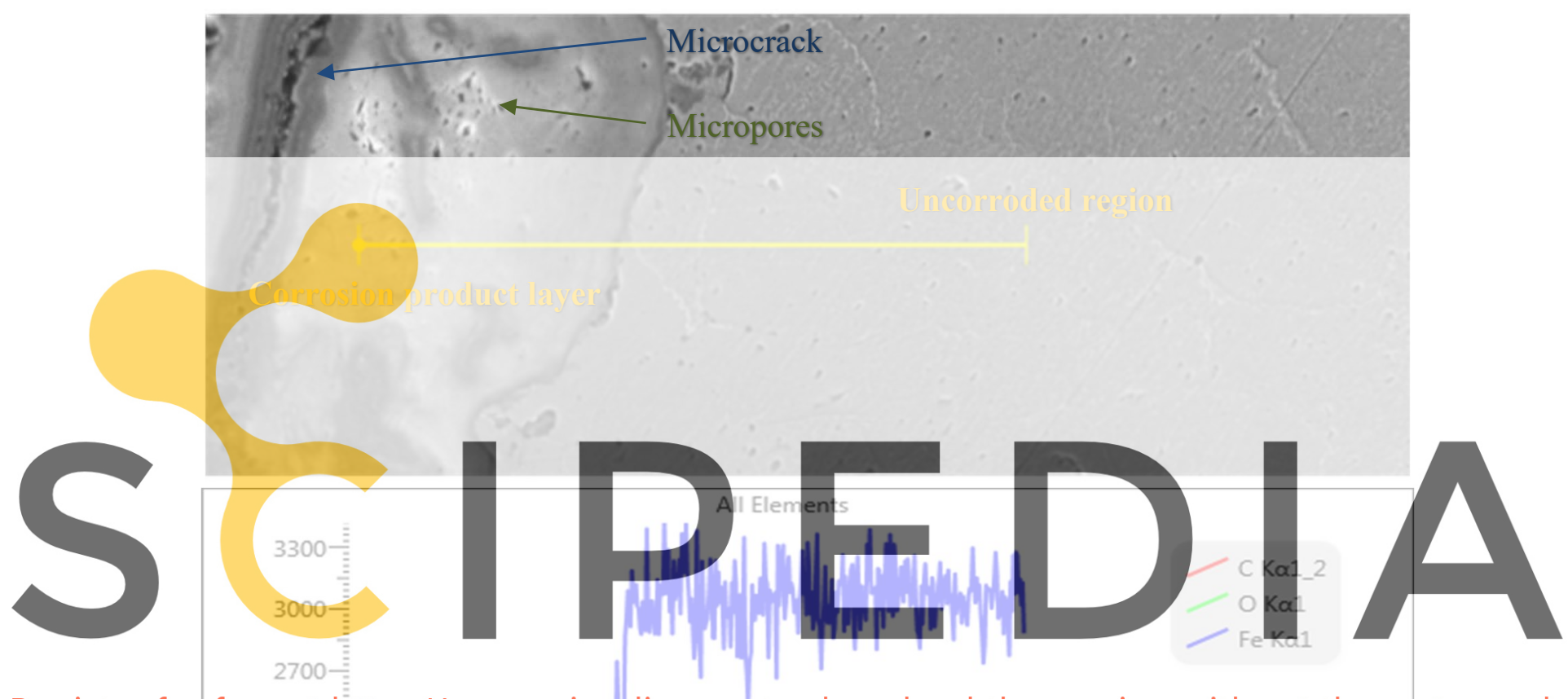

Register for free at

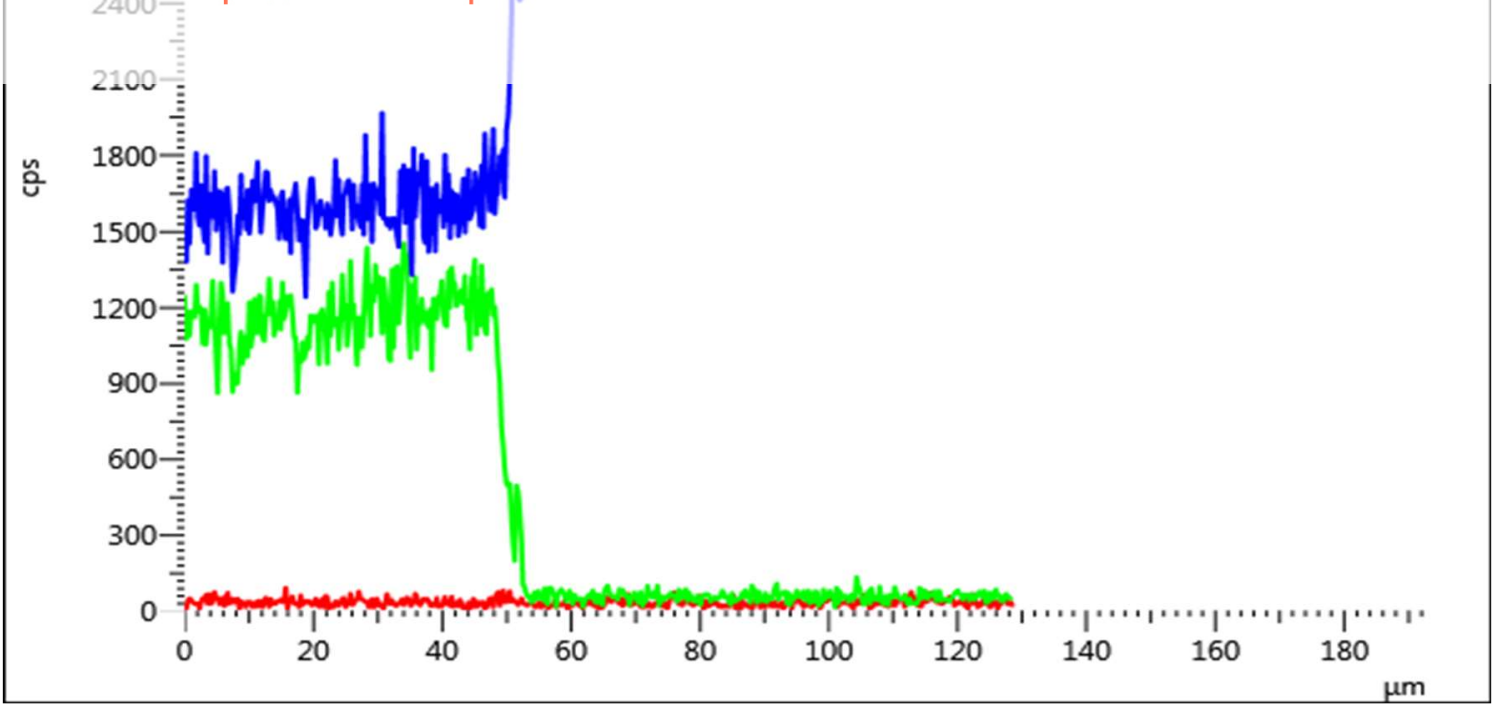

Figure 4. EDS Linescan image. 
Linescan technique showed variation in concentration mainly of oxygen and iron. Noncorroded region of the three samples resulted in high iron concentration and insignificant amount of oxygen. Where the analysis reaches the corrosion layer, the iron concentration drops abruptly and the oxygen concentration rises, thus remaining throughout the corrosion product layer. As the corroded layer is formed by corrosion products, which are composed of different types of oxides and hydroxides, according Gomes and Barreto apud Helene (1993), this high presence of oxygen identifies the presence of these products in the corroded layer.

\subsection{Mechanical Testing}

To finalize the bars analysis, mechanical tensile test was performed, in order to obtain the bars strength limit. It was followed the criteria established by ASTM E8.E8M:2016, which resulted in the following data:

Table 1. Mechanical tensile test.

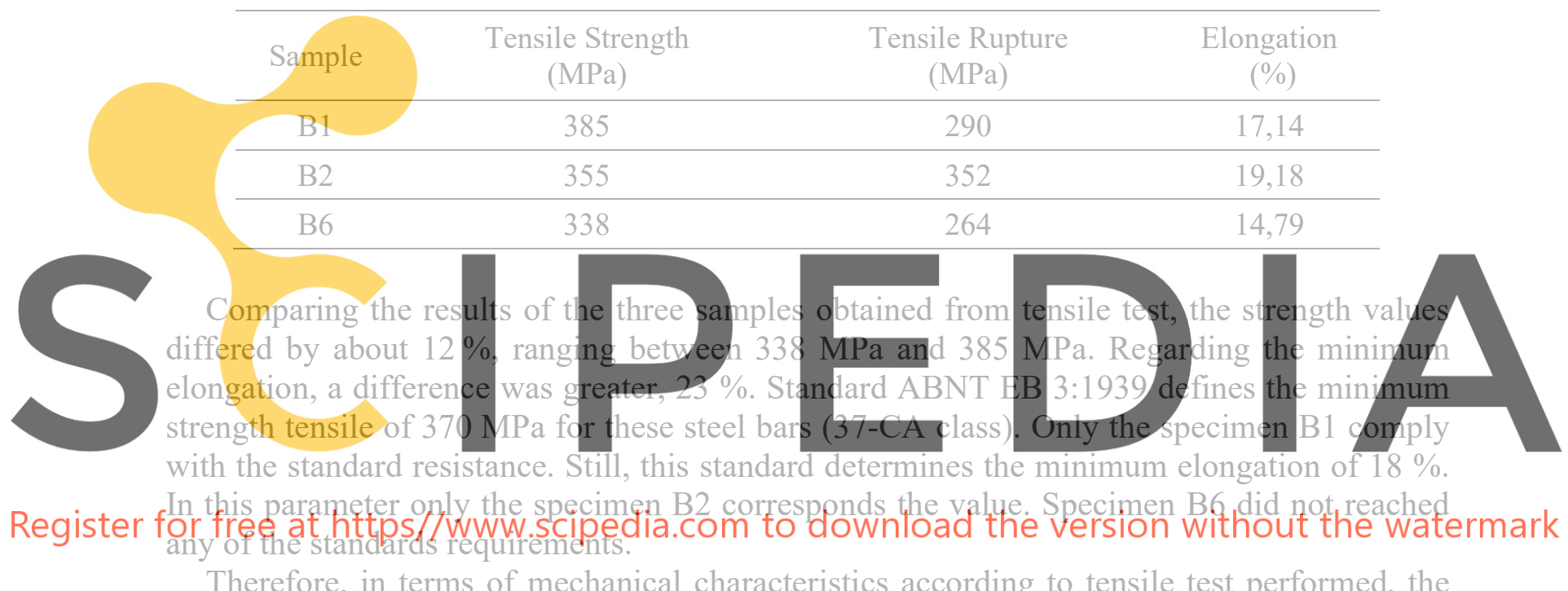

Therefore, in terms of mechanical characteristics according to tensile test performed, the steel bars are not presented in conformity to the current rules, given their state of degradation after about 70 years inside the concrete structure.

\section{Conclusions}

Through microstructural studies, it is possible to visualize the configuration of the material, which presented itself in a homogeneous way, with irregular grain size and shapes. In addition, the presence of grains with two different shades was observed, possibly presenting two distinct phases.

The microstructural analysis also allowed to observe a generalized corrosion process in the studied bars, with some more accentuated corrosion pits. As the corrosion occurred and progressed irregularly from the surface, points with very superficial corrosion depth and other more advanced points were found. This irregular wear can best be seen through the contrast caused by bakelite, showing that the corrosion front in this case did not act uniformly.

Another microstructural analysis was the layer of corrosion products formed on the surface of the bars. This layer presented with varied thickness, from $62.38 \mu \mathrm{m}$ to $381.20 \mu \mathrm{m}$, 
emphasizing that the corrosion does not occur in a uniform way. Still, the fragility of the corrosion products was observed on the surface of the bar, since the layer presented several microcracks and micropores. As shown by Zhang (1996), corrosion products may differ in their composition, structure, morphology and properties, and this will depend on the specific conditions under which the corrosion process occurs, and some are thicker, more voluminous and more porous than others.

Chemical evaluation by EDS, using the Linescan technique, it was clear the high presence of oxygen in the corroded layer, and the abrupt fall as soon as this barrier is overcome, reaching the steel that does not show signals of corrosion. This is justified because the oxygen penetration into the corroded layer is facilitated, due the presence of microcracks, differently of more conserved steel that has less porosity. Furthermore, the corrosion products formed on the surface of the steel bar are various oxides and hydroxides, which provides a high presence of oxygen in this region.

Through the tensile test, sample B1 meets the minimum strength and sample B2 corresponds to the minimum elongation indicated by the standard. However, none of the tested bars showed all results according to the established values.

Finally, all these results showed that, it was possible to notice their advanced corrosion process, after 70 years of the bars aging naturally and with no records of repair in the structures in which the bars were inserted.

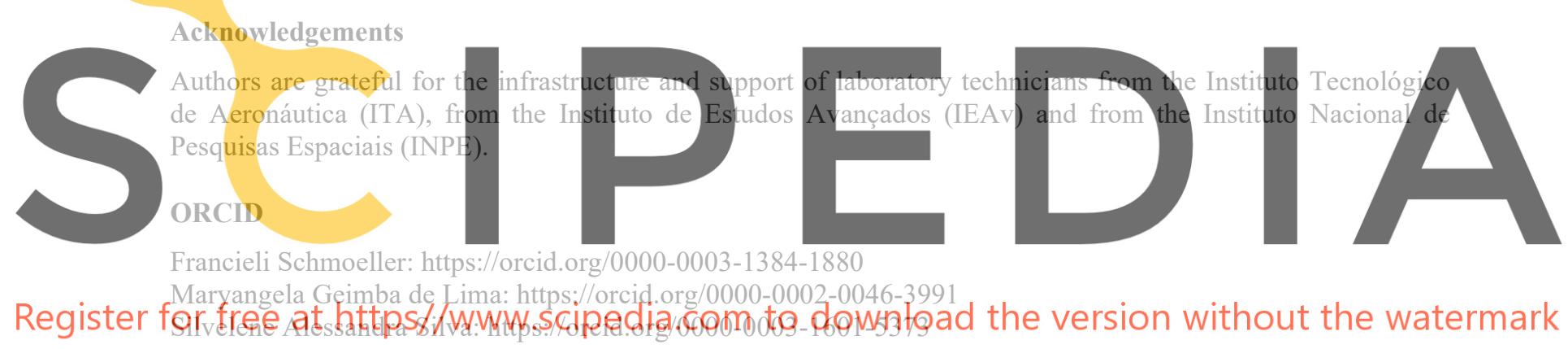

References

American Society for Testing and Materials. (2016). E8/E8M. Standard test methods for tension testing of metallic materials. Pensilvânia.

Associação Brasileira de Normas Técnicas (1939). EB-3. Barras laminadas de aço comum para concreto armado. Rio de Janeiro.

Bossio, A., Monetta, T., Bellucci, F., Lignola, G. P. and Prota, A. (2015). Modeling of concrete cracking due to corrosion process of reinforcement bars. Cement and Concrete Research, 71, 78-92. doi: 10.1016/j.cemconres.2015.01.010

Helene, P. R. L. (1993). Contribuição ao estudo da corrosão em armaduras de concreto armado (in portuguese), PhD Thesis. Escola Politécnica da Universidade de São Paulo (USP), São Paulo.

Koch, G., Varney, J., Thompson, N., Moghissi, O., Gould, M. and Payer, J. (2016). International measures of prevention, application, and economics of corrosion technologies study. Texas: NACE International.

Lima, M. G. (1996). Inibidores de corrosão: avaliação da eficiência frente à corrosão de armaduras provocada por cloretos (in portuguese), PhD Thesis. Escola Politécnica da Universidade de São Paulo (USP), São Paulo.

Mehta, P. K. and Monteiro, P. J. M. (2006). Concrete: microstructure, properties, and materials. New York, NY: McGraw-Hill. 
Pandolfo, F. G. (2006). Análise modal de materiais compósitos (in portuguese), Dissertation. Universidade de Caxias do Sul, Rio Grande do Sul.

Pourbaix, M. (1974). Atlas of electrochemical equilibria in aqueous solutions. Brussels: CEBELCOR.

Schmitt, G., Schütze, M., Hays, G. F., Burns, W., Han, E. Pourbaix, A. and Jacobson, G. (2009). Global needs for knowledge dissemination, research, and development in materials deterioration and corrosion control. World Corrosion Organization, Worldwide.

Souza, V. C. M. and Ripper, T. (1998). Patologia, recuperação e reforço de estruturas de concreto. São Paulo: PINI.

Tuutti, K. (1982). Corrosion of steel in concrete. Swedish Cement and Concrete Research Institute. Stockholm: CBI forskning research.

Zhang X. G. (1996). Corrosion Products. Corrosion and Electrochemistry of Zinc. Boston: Springer.
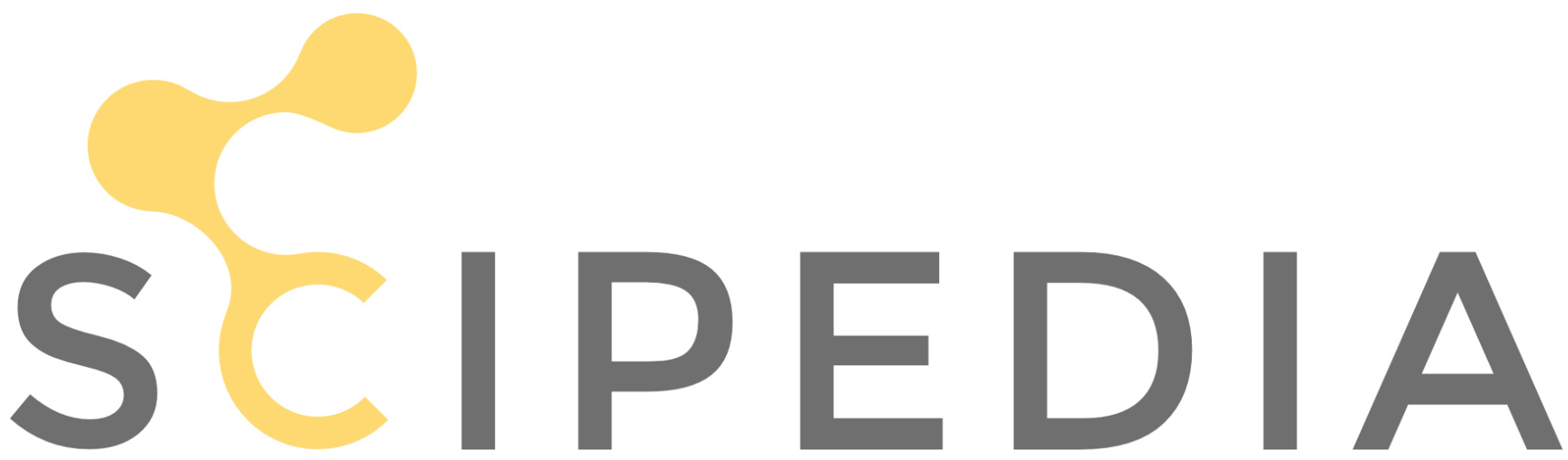

Register for free at https//www.scipedia.com to download the version without the watermark 